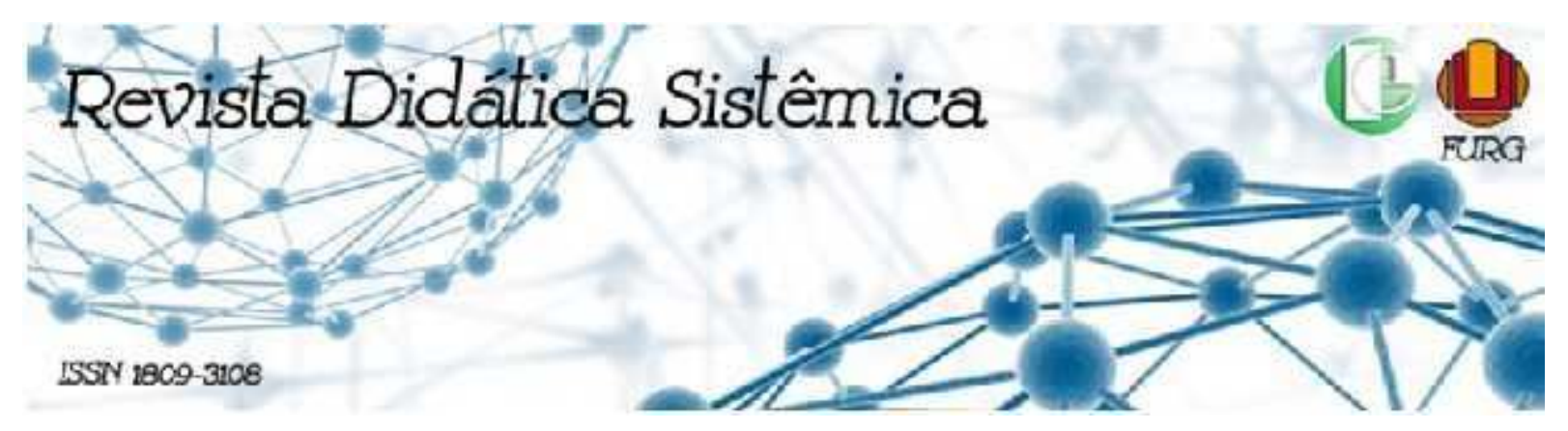

\title{
AS MÚLTIPLAS LINGUAGENS NA EDUCAÇÃO DA INFÂNCIA: EXPERIÊNCIA DE BRINCAR, PARTICIPAR E APRENDER
}

\author{
Adriana Santiago Silva ${ }^{1}$ \\ Andrea de Faria Souza ${ }^{2}$ \\ Claudia Panizzolo ${ }^{3}$
}

\section{RESUMO}

O presente artigo tem por objetivo refletir acerca de possíveis caminhos que considerem as múltiplas linguagens das crianças, contemplando-as como eixo privilegiado das práticas cotidianas da Educação infantil e do Ensino Fundamental. Por meio de pesquisa qualitativa, ancora-se na observação e registros de formação continuada. São analisadas duas experiências, uma sobre formação de professores para o trabalho com materiais heurísticos com bebês e crianças pequenas, e a segunda sobre a formação de professores dos anos iniciais do fundamental sobre a criação de espaços democráticos e participativos

\footnotetext{
${ }^{1}$ Mestranda em Educação pela UNIFESP - Universidade Federal de São Paulo, pós-graduada em Docência do Ensino Superior e Neuropsicopedagogia. Possui graduação em Letras pela Faculdade de Filosofia, Ciências e Letras de São Bernardo do Campo e Pedagogia pela Universidade Bandeirante de São Paulo. Experiência na área de Educação há 22 anos, atuando como docente na área de Língua Portuguesa, além de experiência de 5 anos na área de formação continuada de professores, no cargo de coordenadora pedagógica e 10 anos em gestão, no cargo de diretora escolar. Em 2017 e 2018 exerceu o cargo de gestora na Secretaria de Educação do município de São Bernardo do Campo, atuando como chefe da Seção de Inclusão Educacional. Membro do GEPICH - Grupo de Estudos e Pesquisas: Infância, Cultura e História. Contato: santiago_adriana@yahoo.com.br Link de acesso ao Lattes: http://lattes.cnpq.br/5688235059377682

${ }^{2}$ Mestranda em Educação pelo Programa de Pós-Graduação em Educação na Universidade Federal de São Paulo UNIFESP, Pós- Graduação em Docência do Ensino Superior -FALC; Pós- graduação em Violência Doméstica contra crianças e adolescentes - IPUSP. Possui Graduação em Pedagogia pela Faculdade de Filosofia, Ciências e Letras Fundação Santo André. Experiência na área de Educação há 25 anos, atuando como docente da Educação Infantil na Rede Municipal de Educação de São Bernardo do Campo; 06 de experiência na função de Professora de Apoio Pedagógico da Educação Infantil ( Professora Coordenadora), na Rede Municipal de São Bernardo do Campo; experiencia de 12 anos no cargo de coordenadora pedagógica na Rede Municipal de Educação da cidade de São Paulo; 03 anos de experiência no cargo de Supervisora Escolar na Prefeitura do Município de São Paulo, atualmente é Diretora da Divisão Técnica Pedagógica na Diretoria Regional de Educação São Mateus da Prefeitura do Município de São Paulo. Membro do GEPICH - Grupo de estudos e pesquisas Infância, Cultura e História. contato: andreafariasouza75@gmail.com. ORCID:https://orcid.org/0000-0002-7517-0464 lattes: https://wwws.cnpq.br/cvlattesweb/PKG_MENU.menu?f_cod=A0ECC1C8F3AB9388DE1005A20483B994\#.

${ }_{3}^{3}$ Professora Associado II da Escola de Filosofia, Letras e Ciências Humanas da Universidade Federal de São Paulo- EFLCH / UNIFESP. Docente do Programa de Pós-Graduação em Educação da UNIFESP e do curso de Pedagogia, na área de educação infantil. Pós-doutoramento pela Universidade de Caxias do Sul/ Università degli Studi de Molise- Itália. Coordenadora do Grupo de Estudos e Pesquisa Infância, Cultura, História- GEPICH; membro pesquisadora do Grupo de Estudos e Pesquisa "História da Educação, Imigração e Memoria" GRUPHEIM; membro pesquisadora do Grupo de Pesquisa "TRANSFOPRESS BRASIL- Grupo de Estudos da Impre nsa em língua estrangeira no Brasil"; membro pesquisadora do Grupo de Estudos e Pesquisa História da Educação: intelectuais, instituições, impressos. Contato: claudia.panizzolo@unifesp.br Link de acesso ao lattes: http://lattes.cnpq.br/7842950333039932
} 
no lanche e recreio das crianças. Como conclusão é possível afirmar que o trabalho com as múltiplas linguagens não se esgota na primeira infância, mas ao contrário, constitui-se na superação das práticas pedagógicas transmissivas e na inclusão de vivências e experiências em espaços e territórios do saber capazes de acolher as linguagens infantis.

Palavras-chave: Múltiplas linguagens; Brincadeiras heurísticas; Participação; Formação de professores; Infância.

\title{
MULTIPLE LANGUAGES IN CHILDHOOD EDUCATION: EXPERIENCE OF PLAYING, PARTICIPATING AND LEARNING
}

\begin{abstract}
This article aims to reflect on possible paths that consider the multiple languages of children, contemplating them as a privileged axis of daily practices in early childhood and elementary education. Through qualitative research, it is anchored in the observation and records of continuing education. Two experiences are analyzed, one on teacher training for working with heuristic materials with babies and young children, and the second on teacher training in the early elementary years on the creation of democratic and participative spaces in children's school. As a conclusion, it is possible to affirm that the work with multiple languages does not end in early childhood, but on the contrary, it constitutes the overcoming of transmissive pedagogical practices and the inclusion of experiences in spaces and territories of knowledge capable of welcoming children's languages.
\end{abstract}

Keywords: Multiple languages; Heuristic games; Participation; Teacher training; Childhood.

\section{MÚLTIPLES LENGUAJE EN LA EDUCACIÓN INFANTIL: EXPERIENCIA DE JUEGO, PARTICIPACIÓN Y APRENDIZAJE}

\section{RESUMEN}

Este artículo tiene como objetivo reflexionar sobre posibles caminos que consideran los múltiples lenguajes de los niños, contemplándolos como un eje privilegiado de las prácticas cotidianas en la primera infancia y educación básica. A través de la investigación cualitativa, se basa en la observación y los registros de la educación continua. Se analizan dos experiencias, una sobre la formación del profesorado para el trabajo con materiales heurísticos con bebés y niños pequeños, y la segunda sobre la formación del profesorado en los primeros años de primaria sobre la creación de espacios democráticos y participativos en la merienda y el recreo infantil. Como conclusión, es posible afirmar que el trabajo con múltiples lenguajes no termina en la primera infancia, sino que por el contrario, constituye la superación de prácticas pedagógicas transmisivas y la inclusión de experiencias en espacios y territorios de conocimiento capaces de acoger lenguajes de los niños.

Palabras clave: Múltiples linguajes; Juegos heurísticos; Participación; Formación de profesores; Infancia. 


\section{INTRODUÇÃO}

No quintal a gente gostava de brincar com palavras mais do que bicicleta. Principalmente porque ninguém possuía bicicleta.

A gente brincava de palavras descomparadas. Tipo assim:

O céu tem três letras

O sol tem três letras

O inseto é maior

O que parecia um despropósito

Para nós não era despropósito

(Brincadeiras, X, Manoel de Barros, 2003, p. 41)

No fragmento da obra Memórias inventadas: a infância, Manoel de Barros apresenta as brincadeiras com as palavras como parte do que ele fazia no quintal, lugar de brincar, onde virava e revirava os brinquedos-palavras, e só conseguia compreender o sentido dos movimentos e deslocamentos os que partilhavam daquele brincar particular.

Elegemos este excerto para refletirmos sobre as múltiplas linguagens. As crianças, independentemente se estão matriculadas na creche, na pré-escola ou no ensino fundamental, continuam a ser crianças e, como tal, interagem, aprendem e se expressam para conhecer o seu corpo e o mundo que as rodeia.

Sobre as múltiplas linguagens, destacamos os estudos de Edwards, Gandini e Forman (2016), Faria e Mello (2009), Barbosa, Albuquerque e Fochi (2013). Essas publicações discutem a importância de as crianças se expressarem por meio das múltiplas linguagens (corpo, pintura, dramatização, música, oralidade, poesia, fantasias, ludicidade, dentre tantas outras), bem como indicam possibilidades de exploração conjunta dessas linguagens entre adultos e crianças.

Pautado nessas perspectivas, o presente artigo tem por objetivo refletir acerca de possíveis caminhos que considerem a linguagem das crianças e que viabilizem o trabalho como eixo privilegiado das práticas cotidianas da Educação Infantil e do Ensino Fundamental, por meio de duas experiências relacionadas às possibilidades de as crianças serem e estarem no mundo. A primeira diz respeito à formação de professores para o trabalho com materiais heurísticos com bebês e crianças pequenas, permitindo que possam se manifestar por meio da escolha, exploração e interação a partir de determinados objetos, e, por sua vez, que os professores aprendam a conhecer, ouvir e observar a partir desta proposta. A segunda aborda a experiência vivida com crianças maiores, que puderam participar, democraticamente, da organização de um determinado espaço e tempo escolar, o que fomentou propostas de formação continuada com os professores ao longo do processo, assim como participação das famílias para as tomadas de decisões. 


\section{AS BRINCADEIRAS HEURÍSTICAS E AS LINGUAGENS INFANTIS}

$\mathrm{O}$ atendimento educacional de bebês e crianças bem pequenas, de 0 a 3 anos, em instituições escolares, vêm ampliando de modo significativo as agendas para discussões e pesquisas que referenciam inovações pedagógicas para a infância, capazes de respeitar os direitos fundamentais das crianças. À medida que textos legais como a Constituição Federal do Brasil (1988), a Lei de Diretrizes e Bases da Educação Brasileira (LDB 9394/96), o Estatuto da Criança e Adolescente (Lei $n^{\circ}$ 8069/90), as Diretrizes Curriculares Nacionais da Educação Infantil (DCNEI, 2010), e, mais recentemente, a Base Nacional Comum Curricular (Brasil, 2018) subsidiam e consideram a Educação Infantil como direito da criança e dever dos Estados e Municípios em oferecê-la.

Por considerar a integralidade dos bebês e das crianças pequenas, nos processos de aprendizagens, entende-se que o trabalho da formação continuada é fundamental para mobilizar, nos profissionais da infância, o reconhecimento das linguagens infantis, expressas nas interações, relações e ações, e, para tal, tomou-se, como objeto de reflexão contínua, nos momentos da formação, as experiências educativas oferecidas no cotidiano das creches.

O processo de formação continuada dos profissionais da Educação Infantil realizados nas Diretorias Regionais de Ensino, do município de São Paulo, tem investido em jornadas formativas que potencializem a imagem de criança que os textos Legais e os documentos curriculares nacionais indicam.

As jornadas formativas com os/as profissionais da infância, no município de São Paulo, apresentaram, dentre uma de suas ações, as experiências de planejamento de espaços e materialidades para as brincadeiras heurísticas e interações com bebês. Goldchmied e Jackson (2006, p. 24) nomeiam de brincadeiras heurísticas, pensadas por adultos, com vistas a incentivar a curiosidade infantil, a investigação e a exploração de diferentes objetos e materiais.

A problematização dos espaços e tempos educativos da creche permitiu que educadores fossem desafiados a construir ambientes de interação com os seus bebês e crianças pequenas, em resposta aos encaminhamentos das discussões. Assim, por meio de observações, pesquisas, investigações e reflexões, foi possível construir, de forma colaborativa, conhecimentos distintos sobre como e por que organizar espaços e ambientes para as brincadeiras e interações com objetos diversificados.

Desse modo, a formação sobre as brincadeiras heurísticas buscou atender à perspectiva da homologia dos processos, que, segundo explica Scarpa (1998, p. 43), é “metodologia de 
formação que consiste em experienciar através de todo o processo de formação, as atitudes, modelos didáticos, capacidades e modos de organização que se pretende que venham a ser desempenhado nas práticas pedagógicas com as crianças”. A seguir, a figura 1 ilustra uma estratégia formativa de dispor materialidades e organizar "ensaios" de espaços preparados para brincadeiras heurísticas, realizados no próprio ambiente da formação.

Figura 1 - Proposição de contextos para brincadeira heurística.

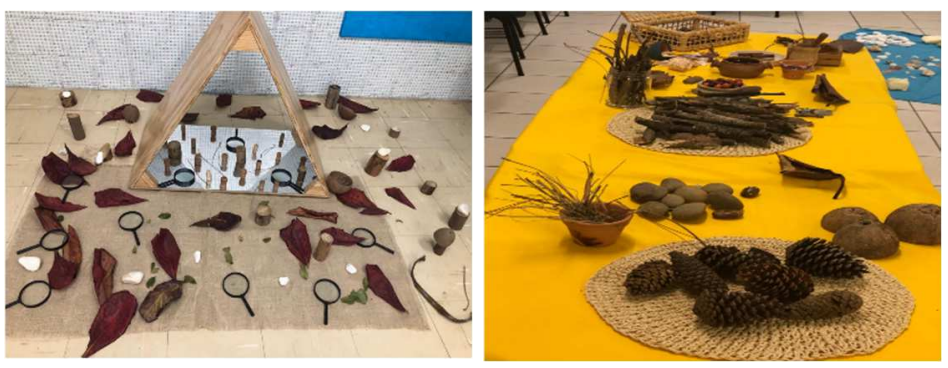

Fonte: Acervo pessoal das autoras - organização das salas para a formação continuada

O trabalho pedagógico com as brincadeiras heurísticas implica assumir uma concepção e imagem de criança potente e capaz, muito distinta das prerrogativas de fragilidade e inocência predominantemente, marcadas em atendimentos assistencialistas e de guarda. Segundo Rinaldi (2012), a imagem de criança que temos dentro de nós foi adquirida por meio de um sistema de representações desenvolvido nas diferentes sociedades, cujas expectativas são dirigidas à criança, por seu contexto social, e, por meio de tais representações, se dão as relações com as crianças. Caminha, neste mesmo sentido, a concepção expressa nas Diretrizes Curriculares Nacionais para a Educação Infantil (BRASIL, 2010), que define a criança como:

Sujeito histórico e de direitos que, nas interações, relações e práticas cotidianas que vivencia, constrói sua identidade pessoal e coletiva. Brinca, imagina, fantasia, deseja, aprende, observa, experimenta, narra, questiona e constrói sentidos sobre natureza e a sociedade, produzindo cultura (BRASIL, 2010, p.12).

Refletir sobre o lugar ocupado por bebês e crianças pequenas, nas instituições educativas, significa assumir como tarefa diária a necessidade de enfrentar algumas crenças e juízos que persistem nas ações e práticas dos profissionais, bem como os modos de relacionarse e atuar com as crianças (FOCHI, 2018, p.19). Ao tratar sobre as experiências cotidianas a se promover com bebês e crianças pequenas, as Diretrizes Curriculares Nacionais da Educação Infantil (DCNEI, 2010) recomendam que os eixos fundamentais das práticas pedagógicas sejam as interações e brincadeiras. 
Segundo afirma o documento Indicador de Qualidade da Educação Infantil Paulistana (SÃO PAULO, 2016), é pela brincadeira que bebês e crianças pequenas se apropriam da cultura e se relacionam com todas as linguagens e formas de simbolização e comunicação: a fala, a encenação, os sons, os movimentos corporais, a música, a pintura, as construções, dentre outras. Os bebês e crianças pequenas não separam o momento da brincadeira do de aprender; esse processo acontece de maneira interligada, assim, é necessário qualificar as oportunidades lúdicas que são oferecidas, uma vez que, quanto melhores forem as brincadeiras, mais prazerosas serão suas experiências, portanto mais significativas (FOCHI, 2018, p.47).

Bebês e crianças pequenas sentem grande impulso por explorar, investigar e descobrir por si mesmos. O que compõe o seu entorno torna-se objeto de curiosidade e interesse, de maneira que tudo se torna passível para a composição de suas brincadeiras e jogos. A partir desta premissa preconizada por diferentes estudiosos, como Jean Piaget, Loris Malaguzzi, Emmi Pikler, Maria Montessori, dentre outros, é que Goldschmied e Jackson (2006) desenvolveram a proposta de jogo ou brincadeira para bebês e crianças pequenas, denominado Jogo Heurístico (FOCHI, 2018, p.60).

Segundo Del Corso et al. (2016, p.14), a etimologia da palavra "heurístico" é grega, deriva de "eurisko" e significa "serve para descobrir ou alcançar a compreensão de algo". Nesse sentido, o trabalho com os elementos heurísticos possibilita a oportunidade de, em suas vivências diárias, interagirem e brincarem com materiais diversificados, como objetos do cotidiano, objetos de diferentes texturas, propriedades, pesos, tamanho, sons, cores, estruturas e propriedades; materiais de largo alcance como pedaços de madeira, pedaços de cano, pedaços de tecidos, cordas, rolhas, elementos da natureza etc. Constitui-se, com isso, a gama de materialidades que podem suscitar brincadeiras e jogos exploratórios capazes de permitir inúmeras experimentações e possibilidades investigativas, tornando essas experiências em contextos ricos de aprendizagens.

Para Fortunati (2017), a atitude natural das crianças de conhecer o mundo, através da exploração e da experimentação ativa, é profundamente significativa. A exploração precede a capacidade simbólica e linguística, representando seu indispensável pressuposto. É nesse mesmo sentido que os arranjos espaciais dispostos, nos momentos da formação continuada, permitiram aos educadores atribuírem novos contornos ao estudo da projeção de espaços para o ambiente da brincadeira heurística. A possibilidade de professores e coordenadores pedagógicos da educação infantil debaterem sobre a constituição de arranjos espaciais dispostos na sala da formação foi uma das estratégias utilizadas para que o olhar dessas profissionais 
fosse convocado a perceber que os espaços planejados podem ou não favorecer o agir e o fazer autônomo dos bebês e crianças pequenas.

Estruturar o espaço da brincadeira heurística demanda do professor da infância uma postura de escuta sistemática aos interesses e curiosidades apresentados por bebês e crianças pequenas em suas manifestações e linguagens infantis. As crianças bem pequenas costumam aprofundar-se em longas pesquisas exploratórias quando encontram a possibilidade de interagir pela brincadeira com objetos não estruturados que causam sedução e interesse. Os materiais, no entanto, precisam ser selecionados a partir da observação do professor. Nesse sentido, a sessão de brincadeiras heurísticas é uma rica abordagem justamente pela rigorosidade metodológica que a pressupõe. O professor necessita de muitos dados da escuta das ações elaboradas por seus bebês, de modo que, só então, seja capaz de reunir uma gama de hipóteses para inferir possibilidades a seu planejamento de trabalho com sessões de brincadeiras heurísticas. Como Fochi (2018) afirma, o momento da sessão de brincadeira heurística é plenamente dos bebês e das crianças pequenas, mas a organização prévia compete ao professor que precisa considerar aspectos como o espaço, a escolha qualitativa e quantitativa dos materiais e a estética de como disponibilizar esses materiais selecionados.

A constituição do ambiente da sessão de brincadeiras heurísticas deve ser pensada de modo que os bebês e crianças pequenas se sintam seguros, acolhidos e dispostos, inclusive, observando as brincadeiras e a exploração elaboradas pelos demais bebês e crianças pequenas do grupo. O professor pode utilizar-se de combinações estéticas na apresentação destes materiais, levando em consideração que o modo como são apresentados tem papel determinante à qualidade das interações que serão construídas pelos bebês e crianças pequenas, como afirmam Dubovik e Cippitelli (2018):

Quando falamos em estéticos, referimo-nos à estética como valor que está
sempre ligado aos processos de conhecimento e no qual têm lugar múltiplas
linguagens: a plástica, a física, a fotográfica, as das ciências naturais. Quando
se monta os contextos, pensamos na relação entre essas diferentes linguagens,
de modo que cada criança encontre nelas canal próprio de expressão, um modo
particular de mostrar a sua inteligência e, ao mesmo tempo, um modo por meio
do qual a escola torne visível seu projeto pedagógico (DUBOVIK;
CIPPITELLI, 2018, p.30).

A proposta da brincadeira heurística firma um contexto pedagógico rico de possibilidades, e a observação e o registro das interações dos bebês e crianças pequenas, certamente, indicarão ao professor os caminhos pedagógicos a trilhar com o grupo para o 
desdobramento de novos projetos de pesquisas do interesse das crianças. A compreensão de que bebês e crianças pequenas aprendem na ação e interação exige dos professores da infância o constante exercício de planificar contextos lúdicos capazes de oferecer inúmeras possibilidades de investigação e de exploração (DUBOVIK; CIPPITELLI, 2018, p.60).

No decorrer da experiência de Educação Continuada vivida junto aos profissionais da infância, foi possível observar experiências de relação entre teoria e prática, "o contato com experiências e reflexões que possam ser úteis à compreensão e a solução dos problemas presentes nas práticas profissionais" (CHRISTOV, 2006, p.31), bem como desafios e aprendizagens sobre as brincadeiras heurísticas.

\section{A PARTICIPAÇÃO DAS CRIANÇAS NO COTIDIANO ESCOLAR POR MEIO DE SUAS DIFERENTES LINGUAGENS}

Embora, para alguns, possa parecer simples pensar as crianças do Ensino Fundamental como crianças, uma vez que a faixa etária não deixa dúvida em relação a isso, a questão, no entanto, apresenta complexidade. Cabe entender a representação de criança e de infância existente, historicamente, nas escolas deste segmento, corroborada por ações que chamam à responsabilidade metas a serem alcançadas, dentre as quais se podem destacar as avaliações de larga escala propostas pelos governos estadual e federal, índices a serem alcançados, entre outras determinações legais específicas exigidas para este público. A necessidade de escolarização, tão presente no Ensino Fundamental, torna-se um importante fator para que a observação das diferentes linguagens que as crianças manifestam para comunicar alegrias, curiosidades, frustrações, tristezas, conquistas, dentre outras, fiquem em segundo plano.

Potencializar espaços que dialoguem de forma propositiva com a infância, favorecendo brincadeiras, diálogo, fala e escuta, torna-se uma ação necessária para que as crianças sejam beneficiadas em suas aprendizagens. A intencionalidade das propostas pedagógicas torna-se imprescindível, assim como o acompanhamento sistemático das aprendizagens a partir das questões e hipóteses levantadas pelas próprias crianças. Nesse sentido, os Projetos Políticos Pedagógicos podem ser aliados na garantia de direitos, uma vez que asseguram, em seus colegiados, a gestão democrática como princípio.

Nessa direção, destaca-se o papel do Conselho Mirim ${ }^{4}$ para a elaboração conjunta de

\footnotetext{
${ }^{4}$ O Conselho Mirim é composto por representação de 2 crianças por turma. Trata-se de um colegiado eleito por seus pares, que se reúne, mensalmente, para discutir questões relativas à unidade escolar e a melhorias necessárias.
} 
planejamento e execução de ações, discorrendo acerca de uma prática ocorrida em uma escola pública municipal de educação básica de ensino fundamental I, localizada na região do $\mathrm{ABC}$ Paulista, na Grande São Paulo, iniciado a partir da observação cotidiana da rotina pela diretora da escola. Olhar os mesmos espaços, geralmente, tão conhecidos, de forma estrangeira, com espanto e estranhamento, é desafiador no dia a dia. Nessa direção, tomou-se por empréstimo o conceito de cotidiano de Certeau (2003):

O cotidiano é aquilo que nos é dado cada dia (ou que nos cabe em partilha), nos pressiona dia após dia, nos oprime, pois existe uma opressão do presente. [...] O cotidiano é aquilo que nos prende intimamente, a partir do interior. É uma história a meio-caminho de nós mesmos, quase em retirada, às vezes velada. [...] O que interessa ao historiador do cotidiano é o Invisível [...] (CERTEAU, 2003, p. 31).

Isto posto, elucida-se, neste texto, um projeto de intervenção que teve como procedimento metodológico inicial observação, a fim de capturar o "invisível" do cotidiano, com vistas à garantia de direitos das crianças. Na sequência, a discussão com o Conselho Mirim a respeito do horário do recreio, dividido em dois momentos: alimentação e brincadeiras, a partir do problema levantado de que muitas crianças não se interessavam sequer em olhar o que seria servido no lanche, preferindo ficar, por vezes, sentadas aguardando o momento da brincadeira, além de grande parte do tempo serem chamadas à atenção por adultos, uma vez que os conflitos eram muitos.

As crianças, ao se serem ouvidas, se queixaram sobre muitas situações, desde a escassez de oferta de materiais para criarem brincadeiras até a qualidade do lanche oferecido. Equipe gestora $^{5}$ e crianças entenderam que era necessário realizar um levantamento minucioso dessa situação, pois, se, por um lado, era importante compreender quantos alunos tinham queixas sobre o recreio, não menos importante era compreender cada uma dessas queixas. Dessa forma, em parceria com as professoras do laboratório de informática, foi elaborado um formulário, utilizando-se a ferramenta google form ${ }^{6}$, possibilitando que todas as crianças pudessem escrever o que pensavam sobre o recreio, com um espaço aberto a críticas e sugestões.

Foram propostas 7 questões para resposta no formulário, da seguinte forma: $1 .^{\text {a }}$ Você se alimenta antes de vir para a escola? 2. ${ }^{a}$ Você sabe que a escola oferece o lanche complementar? (Manhã às $7 \mathrm{~h} /$ Tarde às $14 \mathrm{~h}$ e $17 \mathrm{~h}$ ) $3 .^{\mathrm{a}}$ Você se alimenta no recreio? Por quê? $4 .^{\mathrm{a}}$ No momento do

\footnotetext{
${ }^{5}$ A equipe gestora das unidades escolares do município citado é composta pela direção, vice-direção e coordenação pedagógica.

${ }^{6}$ Ferramenta do Google que possibilita organização de dados.
} 
recreio, de quais tipos de brincadeira você mais gosta? 5. ${ }^{a}$ Quem você procura durante o recreio quando precisa de ajuda? 6. ${ }^{\mathrm{a}} \mathrm{O}$ que mais te incomoda no recreio? 7. ${ }^{\mathrm{a}}$ Sugestões de melhorias.

Todas as crianças participaram desta pesquisa, utilizando o laboratório de informática ${ }^{7}$. As crianças que ainda não apresentavam hipótese de escrita alfabética contaram com o auxílio de seus professores para a escrita. Devido à quantidade de crianças matriculadas na escola (cerca de mil), esse processo teve duração aproximada de duas semanas para ser concluído. Os resultados foram inseridos em planilhas a partir das respostas dos alunos, organizando os dados por categorias, como, por exemplo: horário, espaços, alimentação, brinquedos, brincadeiras, conflitos, entre outras. Uma vez organizados os dados, foram expostos, no pátio da escola (figura 2), dando acesso às crianças, famílias, professores e funcionários.

Figura 2 - Painel de resultado da pesquisa

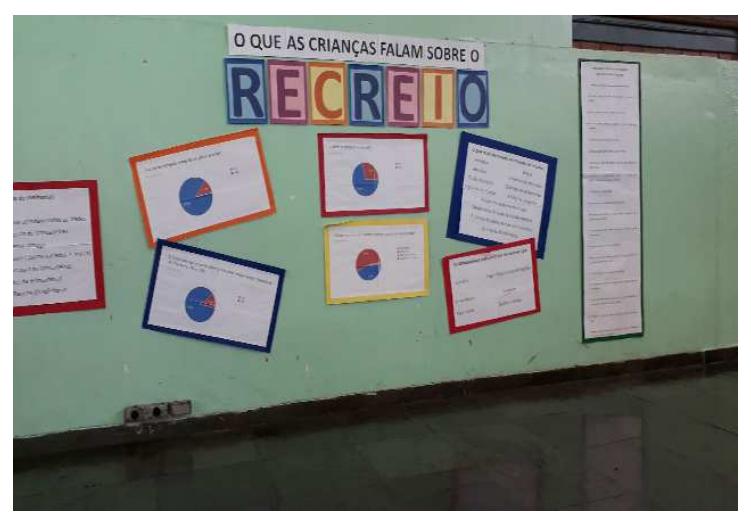

Fonte: Acervo pessoal

Uma das queixas se referia ao momento da alimentação, com solicitação de melhoria da apresentação do espaço, propondo um ambiente mais agradável e acolhedor, o que poderia, inclusive, resultar em uma melhor aceitação da alimentação por parte das crianças. Uma das sugestões foi que todas as mesas possuíssem toalhas. Discutindo mais sobre o tema com o Conselho Mirim, houve a sugestão que as crianças participassem do processo de confecção das toalhas.

Outra queixa apresentada pelas crianças, no tocante ao recreio, foi que realizar a divisão do tempo entre alimentação e brincadeiras gerava uma grande ansiedade, considerando que, por vezes, optavam por não se alimentarem por estarem ansiando pelo brincar ou, ainda, sentiam desconforto em se alimentarem e, na sequência, participarem de brincadeiras que proporcionavam maior movimento corporal, como, por exemplo, pular corda.

\footnotetext{
${ }^{7}$ As escolas de educação básica deste município que atendem crianças do ensino fundamental I possuem laboratório de informática com computadores disponíveis para utilização pelas crianças.
} 
A escuta atenta das crianças possibilitou muitas reflexões e demandas formativas. Larrosa (2007) assevera que a escola é um local que deve "pôr-se à disposição daquele que vem, sem pretender reduzi-lo à lógica que impera em nossa casa” (p. 188). Dessa forma, foi necessário rever a lógica adotada até então pela escola em momentos de reunião com funcionários, professores e famílias.

No que interessa para este artigo, destaca-se a formação de professores durante o Horário de Trabalho Pedagógico Coletivo- HTPC ${ }^{8}$. As discussões correram a partir da leitura das respostas das crianças, aliada aos pressupostos anunciados por Imbernón (2011), que estabelecem "a escola como foco de 'ação-reflexão-ação', unidade básica de mudança, desenvolvimento e melhoria" (p. 82). O autor, também, defende que alguns caminhos podem levar a termo bons resultados ao sugerir "em vez da independência, propor a interdependência; em vez do corporativismo profissional, a abertura profissional; em vez do isolamento, a comunicação; em vez da privacidade do ato educativo, a colaboração" (p. 86).

Os conceitos apresentados por Imbernón (2011), somados aos apresentados por Freire (1992), que pressupõem que a educação, independente de qual seja, é sempre uma teoria do conhecimento posta em prática, convergiram para reflexão e ações possíveis no cotidiano da escola, dando origem a algumas perguntas a respeito da prática docente: Quais formas são possíveis para uma escuta atenta das crianças e que respeitem suas diferentes linguagens? Quais espaços são proporcionados às crianças e famílias para as discussões do cotidiano escolar? Há mudanças que o Projeto Político Pedagógico precise sofrer para garantir o espaço democrático nas tomadas de decisões?

As questões fomentaram, além da observação, a revisitação do Projeto Político Pedagógico e a retomada das formações à luz das discussões de Formosinho; OliveiraFormosinho (2017) e Rinaldi (2012). No tocante à ação-reflexão-ação, houve a reorganização do horário, o que demandou vários desdobramentos, dentre eles, alterar horário e rotina das cozinheiras, o que, em se tratando de cerca de 500 refeições por período, não se traduz em uma tarefa fácil, todavia as alterações necessárias foram realizadas, bem como dialogar com os pais a respeito da mudança a fim de estabelecer um diálogo fluido e transparente.

Envolver a comunidade escolar preconiza a garantia do direito democrático de

\footnotetext{
${ }^{8}$ De acordo com a Resolução SE 01/2019, que regulamenta a carga horária dos professores no município onde a escola se localiza, as horas de trabalho pedagógico coletivo (HTPC) referem-se às horas de trabalho do professor em atividades coletivas, presenciais ou a distância, destinadas ao aperfeiçoamento profissional em consonância com o projeto político pedagógico e com a prática docente. Disponível em https://educacao.saobernardo.sp.gov.br/images/editais_resolucoes/resolucoes/2019/Resolucao_SE_n_01_2019 HTPC_HTPL_e_HTP.pdf. Acesso em 28/07/2020.
} 
oportunizar a fala de todos, destacando-se, aqui, a fala das crianças, que se expressam também através de diferentes linguagens. Faria e Mello (2005) asseveram que: "É democrático oferecer as oportunidades para as crianças aprenderem a ler e a escrever, não tenho dúvida. Mas é democrático também oferecer oportunidades de trabalhar as outras 99 linguagens [...]” (p. 126).

Por conseguinte, foram oferecidas condições para que a pintura das toalhas acontecesse em um sábado letivo ${ }^{9}$, com a presença das famílias na escola. Retalhos de tecidos foram entregues às crianças, que realizaram a pintura juntamente com seus familiares. O desenho foi escolhido livremente pelas crianças, que, após a pintura, penduraram seus respectivos retalhos em um grande varal para que a tinta secasse, conforme é possível verificar na figura 3.

Figura 3 - Varal de retalhos

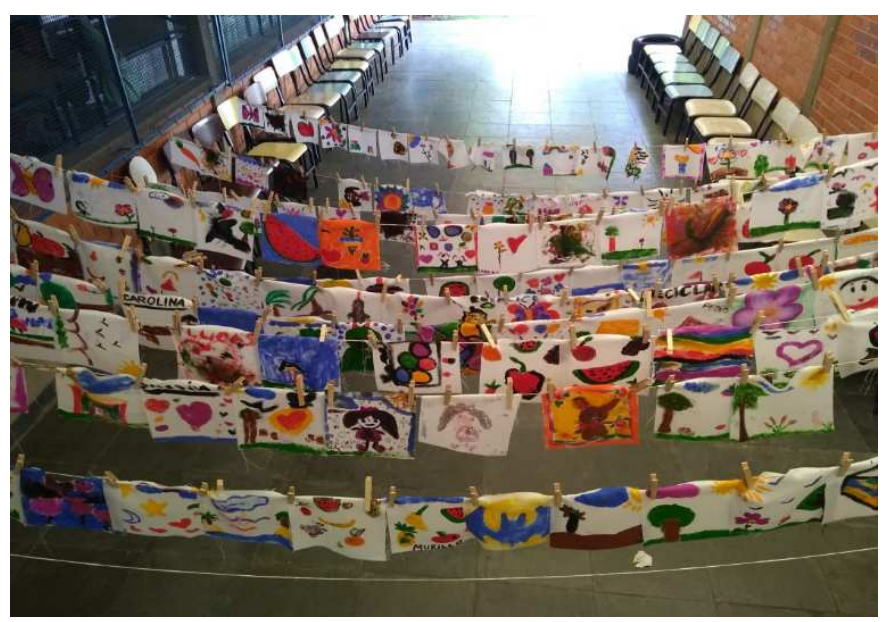

Fonte: Acervo pessoal

Nesse sentido, à luz de uma educação preconizada pela democracia, que garanta, de fato, a participação, conforme anunciado nas palavras de Lück (2005), que "Democracia e participação são dois termos inseparáveis, à medida que um conceito remete ao outro" (p. 54), foi possível envolver toda a comunidade escolar nesta ação, de forma a atingir o objetivo de realização das melhorias necessárias, apontadas pelas crianças, sendo necessário rever práticas e aprender formas diferentes de realizar práticas já cristalizadas na rotina escolar.

\footnotetext{
${ }^{9}$ Os sábados letivos se configuram em momentos de acolhimento das crianças e suas famílias na escola, ocasião em que são propostas atividades conjuntas, mostras culturais e outras possibilidades contempladas nos projetos políticos pedagógicos das unidades escolares.
} 


\section{CONSIDERAÇÕES FINAIS}

A promoção da educação integral como princípio da Educação Básica, no Brasil, constitui-se no grande desafio de assegurar às crianças uma relação integradora entre os diferentes segmentos do ensino que trabalham com crianças, uma vez que as crianças não deixam de ser crianças ao final da Educação Infantil.

Refletir sobre a integralidade dos sujeitos implica o claro reconhecimento de que o trabalho com as múltiplas linguagens não se esgota na primeira infância, mas, ao contrário disso, constitui-se na emergência de superar as práticas pedagógicas transmissivas e a inclusão de vivências e experiências em espaços e territórios do saber capazes de acolher as linguagens infantis.

O lugar da fala, tantas vezes garantido na rotina escolar na roda de conversa, não transforma, de maneira automática, este local em lugar de escuta, ou seja, o cotidiano institucional deve favorecer a participação das crianças, em diversas oportunidades, para se manifestarem por meio das mais variadas linguagens.

Quando se assume que a Educação é um dos caminhos possíveis para a construção de uma sociedade mais justa e igualitária, objetivando a inclusão social, assume-se, também, a responsabilidade de zelar pelos princípios que empoderam esta ação no interior das escolas. Se isto não for observado nas ações cotidianas, em especial, a escuta das crianças e a oportunidade de manifestar-se por meio de diversas e variadas linguagens, a escola não estará a serviço da dignidade humana, perdendo, então, o seu caráter emancipatório.

A partir desta proposição reflexiva, esperançamos.

\section{REFERÊNCIAS}

BARBOSA, M. C. S.; ALBUQUERQUE, S. S. de; FOCHI, P. S. Linguagens e crianças: tecendo uma rede pela educação da infância. Revista Aleph, Niterói/Rio de Janeiro: Universidade Federal Fluminense (UFF) / Universidade Federal do Rio de Janeiro (UFRJ), ano VIII, n.19, p. 5-23, julho. 2013.

BARROS, M. de. Memórias inventadas: a infância. São Paulo: Planeta. 2003.

BRASIL. Ministério da Educação. Secretaria de Educação Básica. Base nacional comum curricular. Brasília: MEC, SEB, 2018.

BRASIL. Ministério da Educação. Secretaria de Educação Básica. Diretrizes curriculares nacionais para a educação infantil. Brasília: MEC, SEB, 2010.

BRASIL. Constituição da República Federativa do Brasil de 1988. Brasília, DF: Presidência da República, 2016. Disponível em: 
Disponível em: http://www.planalto.gov.br/ccivil_03/constituicao/constituicao.htm. Acesso em: 10 jun. 2020.

BRASIL. Lei de Diretrizes e Bases da Educação Nacional, LDB. 9394/1996. Disponível em: Disponível em: http://www.planalto.gov.br/ccivil 03/Leis/L9394.htm. Acesso em 10 jun. 2020.

BRASIL. Lei no 8.069, de 13 de julho de 1990. Dispõe sobre o Estatuto da Criança e do Adolescente e dá outras providências. Diário Oficial [da] República Federativa do Brasil, Brasília, DF. 1990.

Disponível em: http://www.planalto.gov.br/ccivil 03/LEIS/L8069.htm. Acesso em: 23 jul. 2020.

CERTEAU, M. de; GIARD, L.; MAYOL, P. A invenção do cotidiano: 2. Morar, cozinhar. Trad. Ephraim Ferreira Alves e Lucia Endlich Orth. Petrópolis: Vozes: 2003.

CHRISTOV, L. H. S. Teoria e Prática: o enriquecimento da própria experiência. O coordenador pedagógico e a educação continuada. São Paulo: Expressão e Arte, 9 ed., 2006. p. 31-34.

DEL CORSO, J. P. Por meio da exploração e descoberta. In: ESPÍNDOLA, I. et ali. O brincar heurístico. São Paulo: Ateliê Carambola e Ateliê Centro de Pesquisa e Documentação Pedagógica, 2016. p. 14-25.

DUBOVIK, A.; CIPPITELLI, A. Construção e construtividade: materiais naturais e artificiais nos jogos de construção. São Paulo: Editora Phorte, 2018.

EDWARDS, C.; GANDINI, L.; FORMAN, G.(orgs). As cem linguagens da criança: a experiência de Reggio Emília em transformação. Porto Alegre: Penso, 2016.

FARIA, A.L. G. de; MELLO, S. A. (orgs). Territórios da Infância: linguagens tempos e relações para uma pedagogia para as crianças pequenas. $2^{\mathrm{a}} \mathrm{ed}$. Araraquara: Editora Junqueira \& Marin, 2009.

FARIA, A. L. G. de; MELLO, S. A. (orgs.). Linguagens infantis: outras formas de leitura.

Campinas: Autores Associados, 2005.

FOCHI, P. (org.). O brincar heurístico na creche: percursos pedagógicos no Observatório da Cultura Infantil - OBECI. Porto Alegre: Paulo Fochi Estudos Pedagógicos, 2018.

OLIVEIRA-FORMOSINHO, J.; FORMOSINHO, J.; (2017). Pedagogia-em-Participação: a documentação pedagógica no âmago da instituição dos direitos da criança no cotidiano. Em Aberto, Brasília, v. 30, n. 100, p. 115-130, set./dez. 2017.

FORTUNATI, A. (Org.). Por um currículo aberto ao impossível: protagonismo das crianças e educação. Trad. Paula Baggio. Porto Alegre: Editora Buqui, 2017.

GOLDSCHMIED, E.; JACKSON, S. Educação de 0 a 3 anos: o atendimento em creche. 2 ed. Porto Alegre: Artmed, 2006.

IMBERNÓN, F. Formação docente e profissional: forma-se para a mudança e a incerteza. 9. ed. São Paulo: Cortez, 2011.

LARROSA, J. Pedagogia profana: danças, piruetas e mascaradas. 5. ed. Belo Horizonte: Autêntica, 2007.

LÜCK, H. ET AL. A escola participativa: o trabalho do gestor escolar. 5. ed. Petrópolis: Vozes, 2005.

RINALDI, C. Diálogos com Reggio Emilia: escutar, investigar e aprender. São Paulo: Paz e Terra, 2012.

SÃO PAULO. Secretaria Municipal de Educação. Diretoria de Orientação Técnica. Indicadores de qualidade da educação infantil paulistana. São Paulo: SME/DOT, 2016.

SCARPA, R. "Era assim, agora não": uma proposta de formação de professores leigos. São Paulo: Casa do Psicólogo, 1998. 